\title{
OPERATION CONTROL SYSTEM \\ OF STERILIZATION INSTALLATION ON THE BASIS OF THE ACCELERATOR UELV-10-10-S-70
}

\author{
P.A. Bystrov, Yu.S. Pavlov, A.A. Kazyakin, A.A. Kozlov \\ Frumkin Institute of Physical Chemistry and Electrochemistry Russian Academy \\ of Sciences, Moscow, Russia \\ E-mail: bpeter@mail.ru
}

The design of the system for monitoring and recording the operating parameters of the radiation installation at the IPCE RAS on the basis of the accelerator UELV-10-10-S-70 is presented. Solutions are proposed for collecting data from the equipment of the sterilization installation and the accelerator, their primary analysis, transfer to the computer for further processing and fixation in the journal. Presented software of the control device. The created device allows you to timely identify and prevent the occurrence of emergency situations.

PACS: 29.27.Fh

\section{INTRODUCTION}

The irradiation of different health products on radiation-technological installations based on electron accelerators is a demanding task. Life and health may depend on the quality of the work performed, so the problem of continuous monitoring of the irradiation process is urgent. To this end, modern accelerators are necessarily based on a computer that controls the operation of the accelerator and the rest of the installation systems, as well as monitors the irradiation process every second with the help of various systems and sensors.

At earlier sterilization plants, which include the installation of the CCU PMI IPCE RAS based on the UELV-10-10-S-70, the process is controlled manually by operators through continuous monitoring of the instrument readings, which reduces the efficiency of the unit and can cause problems caused by the human factor. Therefore, the development of a system that allows real-time monitoring of the installation on a variety of parameters can significantly increase the efficiency and safety of the irradiation process.

Such a system requires the ability to collect, transmit to a computer and analyze the results of many sensors and devices, record these data, inform about errors and stop the irradiation process in case of abnormal situations. The solution to this problem is to combine different devices and sensors in one system, the formation of each of the sensors informative digital signals for their accumulation and further transmission to a computer for processing.

This system was developed for use at the plant in the CCU PMI IPCE RAS. During installation, the system collects data, displays it on the user's screen, and writes it to a file as a report. In the case of the output parameters of the production process beyond the norm, the signal goes to the operator panel for its intervention, and in the case of emergencies, an emergency shutdown of the system proceeds.

An important task was to maintain the ability to scale the system without significant processing, which allows you to add or remove control devices in the system. Data transmission to computers has traditionally remained a bottleneck even in modern laboratories, where control of equipment is carried out with the help of advanced specialized systems. For these purposes, a simple technical solution of the system consisting of sensors and actuators, universal controller and computer was proposed. For the system the software of the device consisting of two separate parts - software of the controller and software of the controlling computer on the console of operators of the accelerator is developed.

\section{RADIATION INSTALLATION BASED ON THE ACCELERATOR UELV-10-10-S-70}

Center of irradiation in CCU PMI IPCE RAS is based on radiation-technological installation with electron accelerator UELV-10-10-S-70, which is placed in a radiation-safe bunker and is designed for irradiation by an electron beam with an electron energy of up to $10 \mathrm{MeV}$, a beam power of up to $10 \mathrm{~kW}$.

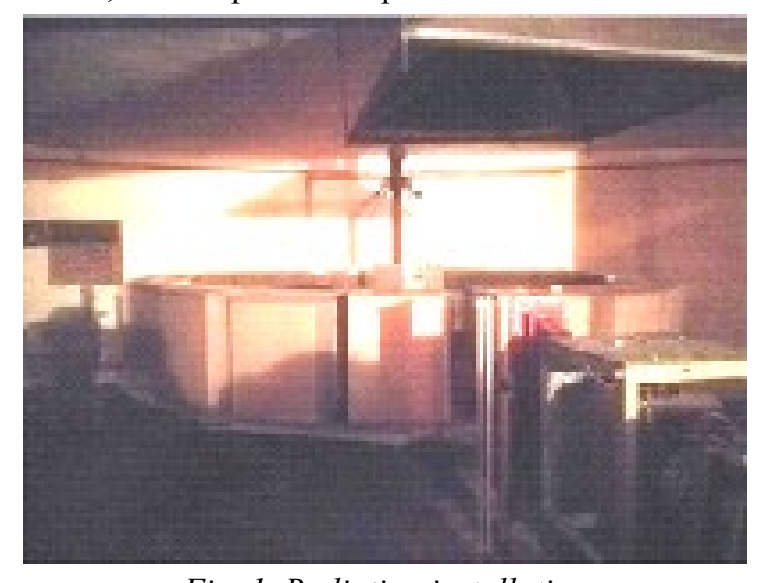

Fig. 1. Radiation installation

in the CCU PMI IPCE RAS

Radiation-technology installation consists of a linear waveguide electron accelerator equipped with a scanning system of the beam, and the circular conveyor that moves objects in front of the output window of the accelerator, at a distance of one meter from the output window. The conveyor with boxes located on it and the output horn of the accelerator scanning system are shown in Fig. 1. The unit is used for various research, technological and commercial purposes [1 - 5].

The developed control system, presented in Fig. 2, collects data from the main units of the installation that affect the result of irradiation. These are data on the movement of the conveyor (the actual and specified speed of rotation of the circular wheel), the waveform of 
the current of the deflecting magnet of the scanning system, the state of the power supply network, the average and pulse current and electron energy of the beam.

The system consists of sensors and pre-conversion boards for outputting analog and digital signals to the controller, the controller itself and the computer. The sensors are installed on the motor controller of the conveyor, on the load-carrying ring of the conveyor, on the scanning system generator, on the power supply feeders of the three-phase network. To control the beam current, an additional sensor is installed - the Faraday cup, which, during operation, is located under the conveyor and measures the beam current at its almost maximum deviation $[6,7]$.

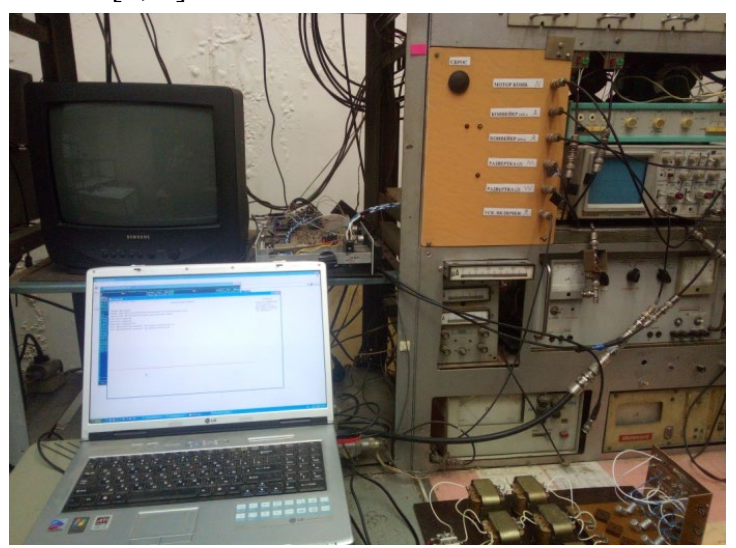

Fig. 2. The control device's blocks on the accelerator console

\section{ELEMENTS OF THE DEVICE FOR CONTROL AND DATA COLLECTION 2.1. UNIVERSAL CONTROLLER}

Solving the problem of simple and efficient data transmission from instruments and sensors on a computer in that device is carried out using an Arduinocompatible AVR controller, shown in Fig. 3. Despite low performance parameters, these controllers have several advantages: simplicity, low cost, versatility, relative's reliability, open architecture, a huge number of all kinds of applications available in open access in the Internet. The controller can receive both digital information from various devices and analog signals using several ADC channels.

The controller can be easily programmed to collect data from a variety of individual instruments and sensors, to preprocess this data and then to transfer it to a computer via the serial port. After receiving the data, the final processing of the data is carried out on the computer with a further transfer of some analysis results back to the controller to execute the necessary commands.

The designed system collects data on the movement of the conveyor to the controller in digital form. The waveform of the voltage at the generator output of the scanning system, the voltage from the controller of the conveyor motor-reducer, the voltage of the supply mains phases, as well as the average beam current data are sent to the controller in the form of analog signals. Each of the sensors in the system is equipped with a pre-conversion card to ensure the safe transmission of analog or digital signals to the controller.

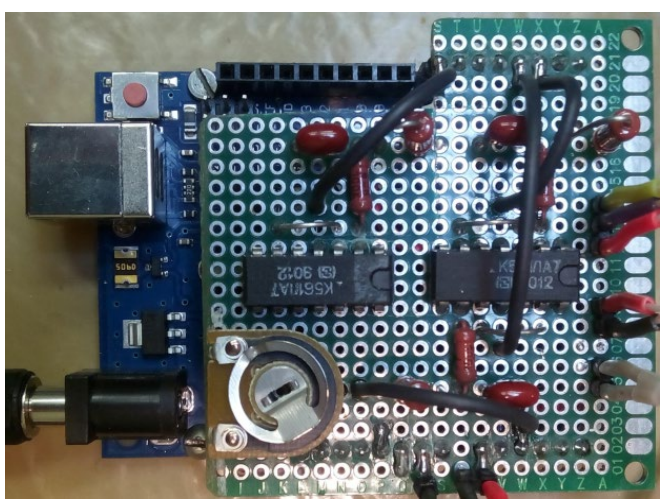

Fig. 3. Universal system controller

Data transmission from sensors to the controller is non-discontinuous, information is transferred from the controller to the computer $10 \ldots 30$ times per second. Processing and recording data of the installation operation in the report is carried out every two seconds. The controller, if necessary, can operate in an oscilloscopemode, allowing to view the source signal from each of the sensors. Waveforms of all data for a certain period of time are stored in a report in case of emergency situations or by the operator's command.

\subsection{ANALYSIS OF MAGNET CURRENT}

The control of the good condition of the scanning system is most important, since the level of the average dose of radiation and its homogeneity depend on it. The failure of the scanning system can lead to foil perforation, loss of vacuum and failure of the accelerator cathode, which leads to serious problems for the entire installation.

The scanning system of accelerator consists of a deflecting magnet, a vacuumed output horn with a beam output foil, and a scanning magnet current generator. The generator is a triple-pole source of triangular or saw tooth shape current with a frequency of $0.5 \ldots 2 \mathrm{~Hz}$. During operation, a triangular form current of frequency current of $0.5 \mathrm{~Hz}$ is generated as standard.

The system continuously monitors the voltage of the scanning system magnet current generator. The constancy of the amplitude and frequency of the current during the entire irradiation process is monitored. In case of failure detection, the system gives the command to switch off the accelerator.

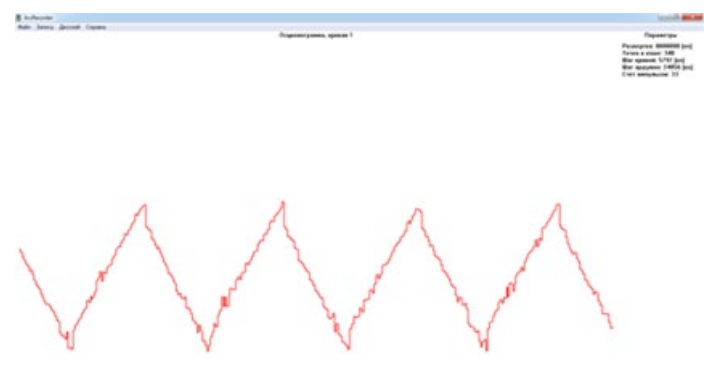

Fig. 4. Waveform of the scanning system current

The sensor of the scanning system contains a voltage converter of a three-pole generator to form a display signal of the relative magnitude of the magnet voltage within $0 \ldots .5 \mathrm{~V}$. The signal from the block is fed to the controller's ADC, in the form of a waveform (shown in Fig. 4), then transferred to a computer and analyzed by software. 


\subsection{CONTROL OF THE INSTALLATION CIRCULAR CONVEYOR}

The installation uses a circular conveyor-horizontal wheel. This conveyor, loaded with boxes is shown in Fig. 1. It rotates across the output window of the accelerator beam. The velocity of rotation of the wheel determines the absorbed dose of the irradiated objects and is the most important parameter for monitoring. Data on the angular position of the wheel is necessary providing the periodic irradiation of objects.

To obtain a given uniform dose, constant monitoring of the position and velocity of rotation of the wheel is required. Stopping the wheel during operation leads to unacceptable overexposure of sterilized objects and is an emergency situation.

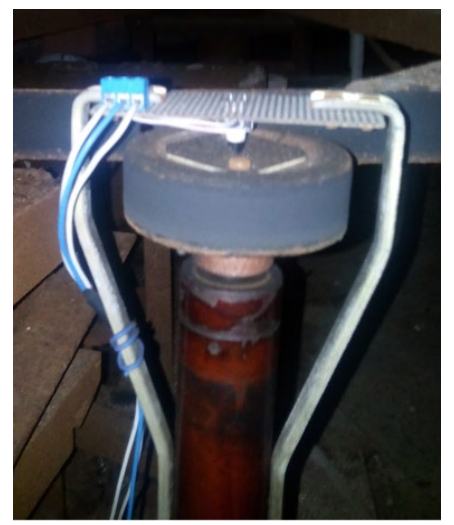

Fig. 5. Conveyer velocity sensor

The system provides simultaneous control of the wheel motor power supply and its actual velocity using a sensor, based on an encoder, presented in Fig. 5. During the period of annual operation, the sensor showed high radiation resistance. The weakness of the sensor is the contact bounce, the electronic filter board is provided to eliminate it.

The control signal from the control unit of the motor goes to the conversion unit, and then to the ADC of the controller. Deviations in the operation of the conveyor are recorded as the difference between the set signal at the controller of the conveyor motor and the measured velocity of the wheel.

\subsection{BEAM PARAMETERS CONTROL}

The control of the accelerator beam parameters is the most complex part of the control system, and this part is under development now. Ideally, the beam parameters sensor should provide the energy spectrum during the entire process of accelerator operation. This requires the development of measurement methods based on the use of equipment that does not affect the process of irradiation at the accelerator $[6,8,9]$.

A simple way to determine the beam parameters is to measure the average current of the whole beam using an induction sensor and the current of a part of the beam deflected at a given angle using the Faraday cup, shown in Fig. 6. This method allows estimating the energy and current of the beam from the empirically found relations.

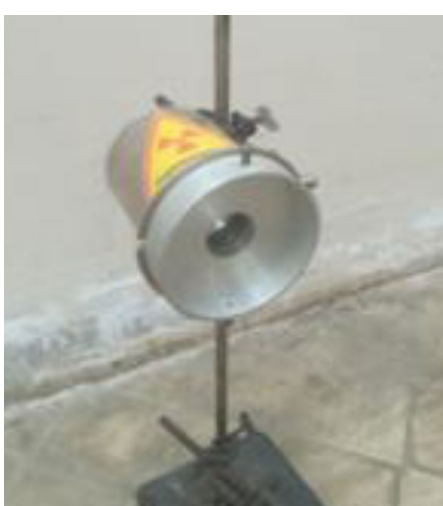

Fig. 6. Faraday cup

The Faraday cup is installed in the zone, located under the accelerator conveyor and measures the current of a part of the beam, deflected on an angle close to the maximum [7]. It uses a part of the beam that does not participate in irradiation, but is necessary to ensure dose uniformity at the edges of the irradiated objects. The ratio of the current from the induction sensor to the current of Faraday cup allows a rough estimate of the average energy and beam current.

The disadvantage of the system is the simultaneous reduction of the average current from the sensor and from the Faraday cylinder with an increase in the electron energy for this type of accelerator, which reduces the measurement accuracy [6]. Measurement accuracy can be increased by accumulating and mathematical post-processing of the collected data, which improves the accuracy of measurements, but it is preferable to refine the measurement method [9].

For processing the pulse signals during their transfer to the controller, a block for integrating the pulses of the beam current has been developed.

In the development of sensors and methods for processing signals from them, simulation is used with the help of the computer code "BEAM SCANNING" [10 12], which was developed to calculate the irradiation processes in radiation technology installations.

\subsection{POWER NETWORK VOLTAGE CONTROL}

Recently, the installation failures related to voltage fluctuations in the power supply network have become frequent. Several useful devices have been developed for tracking voltage instabilities. To detect serious, long-term drops or overvoltage of a three-phase power grid, a network voltage measuring unit was developed, which is based on unstabilized low voltage power supply unit, shown in Fig. 7. The power supply unit generates a signal with a voltage of about $2 \ldots 3 \mathrm{~V}$, which allows to determine the AC amplitude. This signal through the protection system enters the inputs of the controller ADCs, which allows to monitor the voltage drops or excesses in the network at the level of $10 \%$.

The data from the ADCs are analyzed by the controller, in case of signal amplitude being lowered or exceeded, an error message is displayed, the installation equipment is disconnected from the network. 


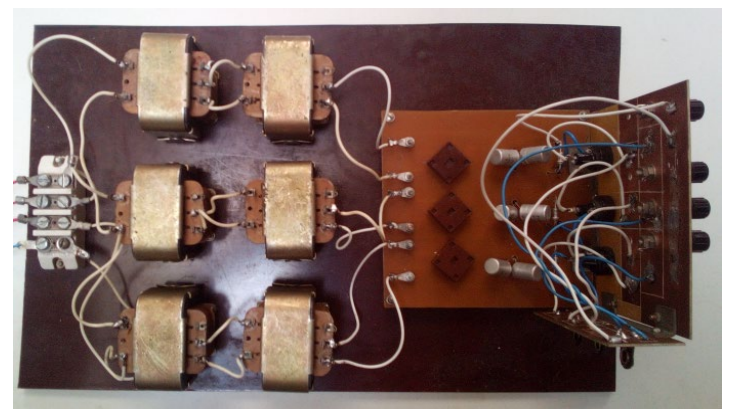

Fig. 7. Three-phase network voltage control unit

\section{THE CONTROL SYSTEM SOFTWARE}

Created system collects data on the movement of the conveyor, the current parameters of the deflecting magnet of the scanning system, the voltage of the power supply network to the controller and then transfers data to the control computer. The software of the system consists of two parts: the software of the controller and the software of the controlling computer.

The controller's software receives and digitizes the analog signals from the sensors and transmits this data to the control computer through the serial port in the form of a matrix of numbers, including the value of the time delay between data transmissions. To save the computational resources of the controller, it implements the minimum functionality in relation to the analysis and recalculation of the data, the controller only collects data and transmits to the computer.

In addition, the controller manages the error signaling and performs equipment shutdown if the corresponding signals come from the control computer.

The computer software provides communicating with the controller via the serial port, decrypting, processing and displaying data streams coming from the controller.

The display of the received data is carried out in the form of the waveforms of each of the channels in accordance with the data transmitted by the controller. Waveforms are analyzed in real time. Every two seconds, the total result is recorded in a file and displayed on the graphic display of the installation. The software is designed for the operating system "Windows XP".

\section{CONCLUSIONS}

A device has been developed for controlling and recording the characteristics of the operation of a radiation installation. A simple method has been proposed for collecting and transmitting data to a computer. The developed version of the system collects data on the movement of the conveyor, the current parameters of the scanning system deflecting magnet, and the voltage in the network.

In the development process is a system of control and accounting for the main characteristics of the accelerator beam: current, average energy, spectrum.

The software of device controller and control computer was developed, that allows data to be collected from multiple devices. Further work on the device implies an increase in the amount of information collected about the operation of the installation, the development of new sensors, and the increase in reliability and convenience of the system.

\section{REFERENCES}

1. P.A. Bystrov, A.V. Gordeev, A.Yu. Kolokolova, et al. Prospects of Electron Beam Irradiation to Ensure Microbiological Safety of Food Products // Physics of Atomic Nuclei. 2018, v. 81, № 10, p. 1526-1530.

2. A.Yu. Gracheova, M.A. Zavyalov, N.V. Ilyukhina, et al. Enhancement of Efficiency of Storage and Processing of Food Raw Materials Using Radiation Technologies // Physics of Atomic Nuclei. 2016, v. 79, № 14, p. 1682-1687.

3. Y.S. Pavlov, A.M. Surma, P.B. Lagov, et al. Accelerator-based electron beam technologies for modification of bipolar semiconductor devices // Journal of Physics: Conference Series. 2016, v. 747, № 1, p. 012085.

4. Y.S. Pavlov, A.A. Revina, O.V. Souvorova, et al. Electron beam agrobionanotechnologies for agriculture and food industry enabled by electron accelerators // Journal of Physics: Conference Series. 2018, v. 941, № 1, p. 012098.

5. V.T. Tarasyuk, A.A. Semkina, V.I. Soloviova, et al. Impact of electron-beam irradiation on multilayer polymer materials: Immediate and long-term (1 year) effects // Physics of Particles and Nuclei Letters. 2018, v. 15, № 7, p. 947-949.

6. P.A. Bystrov, Yu.S. Pavlov, A.A. Kozlov, et al. Radiation installation and accelerator UELV-10-10-S70 beam parameters control, management and registration system // Proceedings of RuPAC2018, Protvino, Russia. JACoW Geneva, Switzerland, 2018, p. 472-474.

7. P.A. Bystrov, Yu.S. Pavlov, O.V. Souvorova, I.Yu. Yakupov. Formation of irradiation beams on accelerator UELV-10-10-S-70 for research of the radiation resistance of polymers // Radiation Physics and Chemistry. 2019, v. 161, p. 83-86.

8. Yu.S. Pavlov, P.B. Lagov. Magnetic Buncher Accelerator for Radiation Hardness Research and Pulse Detector Characterization // 2015 15th European Conference on Radiation and Its Effects on Components and Systems (RADECS). IEEE 2015, p. 336-338.

9. P.A. Bystrov. Applying the computer code beam scanning for obtaining the electron beam energy spectrum and monitoring the beam scanning system with a Faraday cup and edge current sensors // Problems of Atomic Science and Technology. 2014, № 3, p. 193-196.

10. P.A. Bystrov, N.E. Rozanov. The model of the irradiation of a three-dimensional object by the electron beam in the sterilization installation with the local radiation shielding // Problems of Atomic Science and Technology. 2014, № 3, p. 128-133.

11. P.A. Bystrov, N.E. Rozanov. The methodology and the computer code BEAM SCANNING for calculating the processes in the scanning system of electron beam with a broad energy spectrum // Problems of Atomic Science and Technology. 2012, № 4, p. 87-91.

12. P.A. Bystrov, Yu.S. Pavlov, A.V. Prokopenko, et al. Computer program "BEAM SCANNING" for calculation of irradiation processes in radiationtechnological installations // Procedia Computer Science. 2018, v. 145, p. 123-133.

Article received 04.10.2019 


\section{УСТРОЙСТВО КОНТРОЛЯ РАБОТЫ СТЕРИЛИЗАЦИОННОЙ УСТАНОВКИ \\ НА БАЗЕ УСКОРИТЕЛЯ УЭЛВ-10-10-С-70}

\section{П.А. Быстров, Ю.С. Павлов, А.А. Казякин, А.А. Козлов}

Представлена конструкция системы контроля и регистрации параметров работы радиационной технологической установки ИФХЭ РАН на базе ускорителя УЭЛВ-10-10-С-70. Предложены решения для сбора данных с оборудования стерилизационной установки и ускорителя, их первичного анализа, передачи на ЭВМ с целью их дальнейшей обработки и фиксации в журнале. Представлено программное обеспечение устройства контроля. Созданное устройство позволяет своевременно выявить, а также предупредить возникновение нештатных ситуаций.

\section{ПРИСТРІЙ КОНТРОЛЮ РОБОТИ СТЕРИЛІЗАЦІЙНОЇ УСТАНОВКИ НА БАЗІ ПРИСКОРЮВАЧА УЕЛВ-10-10-С-70}

\section{П.А. Бистров, Ю.С. Павлов, А.А. Казякін, А.А. Козлов}

Представлено конструкцію системи контролю та реєстрації параметрів роботи радіаційної технологічної установки ІФХЕ РАН на базі прискорювача УЕВЛ-10-10-С-70. Запропоновано рішення для збору даних 3 устаткування стерилізаційної установки і прискорювача, їхнього первинного аналізу, передачі на ЕОМ з метою їхньої подальшої обробки і фіксації в журналі. Представлено програмне забезпечення пристрою контролю. Створений пристрій дозволяє вчасно виявити, а також попередити виникнення позаштатних ситуацій. 